\title{
HUELLAS CLÁSICAS EN LA POESÍA FUNERAL ESPAÑOLA (EN LATÍN Y ROMANCE) EN LOS SIGLOS DE ORO 1
}

\author{
Antonio Ramajo Caño. \\ Universidad de Salamanca.
}

No pretendemos en este trabajito exhaustividad alguna. Nos contentamos con presentar algunos textos y señalar, sin un análisis demorado, ciertos materiales clásicos de la poesía funeral en latín y romance en los Siglos de Oro. Aludimos con frecuencia a la poesía escrita en latín porque en la vertebración de determinados recursos retóricos no caben fronteras simplificadoras.

1 Para la poesía funeral española, cf. E. Camacho Guizado, La elegía funeral en la poesía española, Madrid, Gredos, 1969, libro abundante en material estudiado, que no estudia, con todo, los precedentes clásicos en los poemas hispanos. Cf. también, para un territorio concreto, F. Rico, "Las endechas a la muerte de Guillén Peraza", Textos y contextos. Estudios sobre la poesía española del siglo XV, Barcelona, Crítica, 1990, páginas 95-158, trabajo lleno de notas sobre la poesía funeraria del Medievo, con copiosa bibliografía. Y es que la huella clásica en la poesía funeral española empieza en la Edad Media. A propósito del epitafio de Sancho de Castilla, muerto en 1071, en el monasterio de Oña, dice el propio Rico: "Un Homero lejano y desteñido tenía en mente el monje que asi lloraba al rey don Sancho" (ap. Breve biblioteca de autores españoles, $3 .^{\mathrm{a}}$ ed., Barcelona, Seix Barral, 1991, pág. 273). Reproduzcamos aquí ese epitafio: "Sanctius, forma Paris, et ferox Hector in armis, / clauditur hac tumba, iam factus pulvis et umbra. / Femina mente dira, soror, hunc vita expliavit; / iure quidem dempto, non flevit fratre perempto" (Ibid.). Cfr. como nuevo ejemplo medieval con raíces clásicas, el epitafio del infante García, en Oña: "Hic aetate puer Garsias, Absalon alter, / fit cinis: illud erit qui gaudia mundi quaerit, / Mars alter, durus bellis, erat ipse futurus, / sed fati series, tunc prius occubuit." Ap. Rico, "Las letras latinas del siglo xII en Galicia, León y Castilla", Abaco, Madrid, Castalia, 1969, vol. 2, págs. 9-91 (pág. 70, nota 123). Se trata de un ejemplo de mors inmatura. Cf. ya un caso de literatura en romance: Libro de Alexandre: "Pitafio" de Aquiles, c. 329: "Achiles so, que yago so est mármol çerrado, / el que ovo a Ector el troyano rancado; / matóme por la planta Paris el perjurado, / a furto, sin sospecha, yaziendo desarmado" (ed. de Cañas, Madrid, Cátedra, 1988, pág. 201. Cf. ibid. la fuente del epitafio). Es frecuente poner en los epitafios el nombre del autor de la muerte. Cf. Amadís de Gaula, lib. I, cap. XIV: "Y después a 
Poesía en lengua latina y poesia en romance caminan por sendas estrechamente paralelas: como que algunos poetas cultivan ambas lenguas (ejemplo eximio es Garcilaso).

Hemos estructurado nuestro trabajo sobre la consideración de cuatro aspectos. En primer lugar, estudiamos la poesía funeral en el marco de la égloga pastoril. Al hacerlo, necesariamente tenemos que tratar del género de los epitafios, y dedicaremos algunas lineas también al estudio de aquellos que podriamos llamar exentos, es decir, que aparecen fuera del marco eglógico. En segundo lugar, nos referiremos a ciertas elegías y a algún soneto de contenido funeral. Este enlace, aparentemente tan artificioso, puede explicarse en tanto que, según diremos después, los sonetos eran considerados como "traducciones" de los epigramas, modelos, a su vez, al menos para algunos, generadores de las elegías. En tercer lugar, estudiaremos dos plantos de inspiración virgiliana. Terminaremos con algunas notas al famoso soneto quevedesco "Amor más poderoso que la muerte", al que insertaremos en la tradición de la poesía funeraria. De esta manera, creemos dejar constancia de una buena variedad de modalidades de este tipo de poesía, siempre con la preocupación de encontrar sus raices clásicas.

1. Comencemos, pues, con el análisis de algunos poemas que sitúan el contenido funeral en el marco de la égloga. Estamos en los momentos áureos del Humanismo. Garcilaso de la Vega pretende aclimatar las huellas clásicas en la poesía romance. Si nos fijamos solamente ahora en la poesía funeral, veremos que en la Égloga $\mathrm{III}^{2}$ el toledano introduce el género del epitafio,

\footnotetext{
tiempo fue allí [en el epitafio] puesto el nombre de aquel que lo venció" (ed. de J. M. Cacho Blecua, Madrid, Cátedra, 1987, pág. 376). Los versos antes citados nos hablan, en fin, de las causas de la muerte del difunto, con un aire de queja. Nos recuerdan dos epitafios que encontramos en las Heroidas ovidianas: el de Filis y el de Dido (cf., respectivamente, II, vv. 146-48, y VII, 194-96. Para otros epitafios medievales, cf. J. Amador de los Ríos, Historia critica de la literatura española, reimpr., Madrid, Gredos, 1970, vol. II, págs. 333-51.

Para la poesía funeral en Grecia y en Roma, cf. A. Ramírez de Verger, "La consolatio en Frontón: en torno al de nepote amisso", Faventia, 5, 1983, págs. 68-70; R. Lattimore, Themes in Greek and Latin Epitaphs, Urbana, 1962. Para el estudio de la poesía funeral latina desde la vertiente cristiana, $\mathrm{cf}$. Ch. Favez, La consolation latine chrétienne (Paris, 1937).

2 Como se va a ver, la cosecha que presentamos referida a Garcilaso es escasa. No podemos aquí detenernos más. Digamos, con todo, que en la Égloga III (vv. 189-91, pág. 200, ed. cit. de Rivers), Garcilaso anota cómo Venus otorga el último beso a Adonis, moribundo, a la manera clásica. Para el estudio, excelente, de las fuentes de este pasaje, cf. el comentarista Tomás Tamayo de Vargas (1622), en Garcilaso de la Vega y sus comentaristas, ed. de A. Gallego Morell, Madrid, Gredos, 1972, pág. 654. Este beso postrero del moribundo, de estirpe clásica, tiene otros ecos en nuestras letras. Luego veremos su plasmación en el poema en latín de Blas López. Digamos ahora que también aparece en Los trabajos de Persiles y Sigismunda de Cervantes (cf. lib. I, cap. XX,
} 
que de por si encierra ya la idea de la consolatio, en cuanto tiene una voluntad de eternizar la memoria del difunto ${ }^{3}$. Garcilaso introduce el epitafio en el marco de un poema bucólico. Sin duda, encontramos aqui un procedimiento que recuerda la Égloga $\mathrm{V}$ de Virgilio ${ }^{4}$. Alli, dos pastores, Mopso y $\mathrm{Me}-$ nalcas, lamentan la muerte de Dafnis ${ }^{5}$ y cantan su apoteosis, la subida a los cielos. Garcilaso ha encargado a una de las ninfas protagonistas de su poema, a Nise, que borde un cuadro en el que se refleje la muerte de Elisa, Elisa joven, "antes del tiempo y casi en flor cortada" 6 . Garcilaso introduce, con este verso, el topos de la frecuentísima mors inmatura, aliado con otro tópico, el de la flor tronchada ${ }^{7}$. Y asi como todos los pastores se entristecieron por

pág. 145 ; lib. III, cap. XIV, pág. 374, ed. de Juan Bautista Avalle-Arce, Clásicos Castalia, 12, Madrid, 1969).

Para el estudio de las huellas clásicas en la Elegía I de Garcilaso, cf. F. Rico, Breve biblioteca, cit., págs. 280-86.

3 Ello se observa explícitamente - permítasenos el salto cronológico- en las palabras que Octavio dirige a la difunta Mariene, esposa de Herodes, en El mayor monstruo del mundo, los celos de Calderón de la Barca: "Hermoso sol caduco, / pues que no puedo vengarte, / yo haré eterna a los futuros / siglos tu fama, diciendo / la inscripción de tu sepulcro: / 'La inocente Mariene / dio fin, cumpliendo su influjo / injustos celos, que son / el mayor monstruo del mundo'" (acto III). Cf. Calderón de la Barca, Tragedias, vol. 1, ed. de F. Ruiz Ramón, Madrid, Alianza Editorial, 1967, pág. 587. Este epitafio tiene un tono ovidiano: cf. nota 1 . A veces, el afán de eternizar al difunto no se ejerce con ánimo benévolo: se pretende dejar constancia de su maldad. Cf., como ejemplo, el epitafio de Sannazaro al papa Alejandro VI (Epigrammata, lib. II, n. ${ }^{\circ} 29$, apud F. Arnaldi y L. Gualdo Rosa: Michele Marullo, Poliziano, Iacopo Sannazaro, Poesie latine, Torino, Giulio Einaudi, 1976, t. II, pág. 224).

4 Para el influjo de Virgilio en las letras españolas, cf. M. Morreale, "Spagna", art. en Enciclopedia virgiliana, Roma, 1988, vol. IV, págs. 953-72; A. Blecua, "Virgilio en España en los siglos xvi y xvII", en Studia virgiliana. Actes del VI Simposi d' Estudis Clàssics 11-13 de febrer de 1981, Bellaterra, 1985, págs. 61-77. Cf., ya para Garcilaso y Virgilio, S. Reisz de Rivarola, "Transferencias poéticas: Garcilaso de la Vega y su 'imitación' de la bucólica virgiliana", Iberoromania, 6, 1980, págs. 86-121.

5 Sobre Dafnis, cf. M. Fernández-Galiano, Títiro y Melibeo, La poesía pastoril grecolatina, Madrid, Fundación Pastor, 1984, págs. 35-36.

6 V. 228, ed. de E. L. Rivers (2.a ed.), Clás. Castalia, 6, Madrid, 1972, pág. 202. El episodio de Elisa muerta se inspira probablemente en un cuadro de Piero di Cósimo, sobre la muerte de Procris a manos de su esposo Céfalo (cf. L. A. Cuenca y M. Brioso en su trad. de Calímaco, Himnos, epigramas y fragmentos, Biblioteca Clásica Gredos, 33, Madrid, 1980 , pág. 57 , nota 44 ).

7 Sobre este tópico volveremos luego. Es uno de los elementos compositivos de los textos funerales en la poesía y en los epitafios clásicos. Para ejemplos, en la época griega, cf. Epigramas funerarios griegos, trad. de M. ${ }^{a}$ Luisa del Barrio Vega, Biblioteca Clásica Gredos, 163, Madrid, 1992, págs. 29-32. Cf. este epitafio romano (de época republicana, única datación dada por la editora que citamos): "Quam coluit dulci gavisus amore puella / hic locat infelix, unica quei fuerat / dum contracta sinunt fatorum tempora numphe", vv. 3-5, Corpus Inscriptionum Latinarum, I/2, 1222, apud Iscrizioni funerarie romane, ed. de Lidia Storoni Mazzolani, Milano, Rizzoli, 1991, pág. 17. A veces el topos se invoca como protesta contra un destino cruel (implícitamente aparecía en los versos anteriores). Asi, Orfeo pretende deshacer una "injusticia": la muerte prematura de Eurídice ("in quam calcata venenum / vipera diffudit crescentesque abstulit annos", 
la muerte de Dafnis, asi también ahora aparecen entristecidas "las silvestres diosas", "todas con el cabello desparcido" ", verso descriptivo que nos remite a otro modelo de composición funeral: el trenos, composición en la que predomina la lamentatio, con alusiones elogiosas al difunto, pero con ausencia de consolatio $^{9}$. Y las muestras de homenaje de los pastores y de las ninfas son idénticas. Si Virgilio invitaba a los pastores con la expresión "spargite humum foliis" 10, Garcilaso nos dice que las diosas traían "cestillos blancos de purpúreas rosas, / las cuales esparciendo derramaban" ". Sí, la huella de la Égloga V virgiliana es evidente; pero también hay, creemos, otra huella del propio vate latino. Garcilaso se acuerda, en efecto, del libro VI de la Eneida, de aquel pasaje en que Anquises, visitado por Eneas, lamenta el fin prematuro - nótese, de nuevo, el tema de la mors inmatura - de Marcelo, el destinado a suceder a Augusto. Recordemos sólo algunos versos famosísimos: "Heu, miserande puer! —exclama Anquises- si qua fata aspera rumpas! / Tu Marcellus eris. Manibus date lilia plenis, Purpureos spargam flores..." ${ }^{12}$. Anquises, pues, pide también púrpureas flores para el joven Marcelo, a cuya muerte escribió un poema Propercio. Y si en la Éloga V Virgilio introducía un breve epitafio: "Daphnis ego in silvis, hinc usque ad si-

Met., X, 23-24). Es topos frecuentísimo en Marcial (cf. Epigrammaton libri, I, 88, 101; V, 34, 37; VI, 28, 85; IX, 74; X, 61; XI, 91). También Garcilaso se sirve de este tópico en otro lugar, en referencia a Elisa (Égloga I, 258-61): " Oh miserable hadol / ¿Oh tela delicada, / antes del tiempo dada / a los agudos filos de la muerte!"

El tópico de la mors inmatura puede aliarse, en efecto, al de la flor tronchada. Véanse los ejemplos que propone Laguna, ed. y trad. de Estacio, Silvas III, Madrid, Fundación Pastor de Estudios Clásicos, 1992, pág. 289. Añadiremos nosotros, además, otro lugar de Garcilaso, al cual luego nos referiremos: Egloga, II, 1253-67.

La mors inmatura aparece frecuentemente en la poesía del Conde de Villamediana. Cf. los sonetos V, IX, XII, XIII, XIV, XVI, en el que hábilmente se introduce el tópico de la oposición puer/senex : el fallecido, muerto en juventud, era provecto por sus cualidades morales ("en tiempo no, en prudencia ... cano", v. 9). Cf. Conde de Villamediana, Poesía, ed. de M. ${ }^{\text {a }}$ T. Ruestes, Barcelona, Planeta, 1992, pág. 228.

8 V. 225 , ed. de Rivers, pág. 202.

- Para esta inserción de elementos propios del trenos en otro tipo de composición funeral, cf., por ejemplo, Estacio, "Consolatio ad Claudium Etruscum", Silvas, III, vv. 8-9, 18-21, 131-37 y 175-79; y "Epicedion in Priscillam", Silvae, V, 1, vv. 20-23. Cf. G. Laguna, ed. cit., págs. 259, 289 y 295. Curiosamente, en Virgilio (Eneida, VII, 503) encontramos un caso de expresión propia del trenos, en el lamento por un animal: Silvia gime ante su ciervo herido por Ascanio palmis percussa lacertos.

10 Bucólicas, V, 40. Es expresión que, por cierto, acoge Marullo en una composición latina. Cf. Epigrammaton libri, I, 33, v. 1, en M. Marullo, Carmina, ed. de A. Perosa, Turici, In aed. Thesauri Mundi, 1951, pág. 14.

11 Vv. 222-23, ed. cit., pág. 202. Claro que a Dafnis también lo llora su madre con lamentos que recuerdan y anticipan los que luego proferirá la madre de Euríalo. Para este paralelismo y para las fuentes griegas de la presencia de la madre en el duelo, verdadera escena de una Piedad pagana, cf. V. Cristóbal, Virgilio y la temática bucólica en la tradición clásica. Tesis Doctoral, Madrid, Univ. Complutense, 1980, pág. 427.

18 Vv. 882-84. 
dera notus, / formosi pecoris custos formosior ipse" ${ }^{13}$, Garcilaso en la Égloga III dedica toda una octava real al epitafio de la ninfa: "Elisa soy, en cuyo nombre suena / y se lamenta el monte cavernoso, / testigo del dolor y grave pena / en que por mi se aflige Nemoroso, / y llama Elisa; Elisa a boca llena / responde el Tajo, y lleva presuroso / al mar de Lusitania el nombre mío, / donde será escuchado, yo lo fío" ${ }^{14}$. En ambos epitafios encontramos, en prosopopeya, al difunto que habla, y que, hemos de entender, se dirige al viandante ${ }^{15}$. Nótese, todavía, un paralelismo entre los dos epitafios: ambos protagonistas son conocidos, su nombre es conocido por largos espacios; pero Dafnis llega hasta las estrellas con su nombre (en realidad, está entre las estrellas) ${ }^{16}$, ha superado no sólo fronteras espaciales, sino temporales, es inmortal; de Elisa sólo sabemos de su fama espacial: nada se aventura de una posible inmortalidad. Claro que el epitafio de Elisa ha de completarse con algunos versos de la Égloga I, aquellos en que dice Garcilaso: "Divina Elisa, pues agora el cielo / con inmortales pies pisas y mides, / y su mudanza ves, estando queda ..." ${ }^{17}$. Aquí encontramos ya un motivo clásico de la consolatio ${ }^{18}$, el de la creencia en una vida futura ${ }^{19}$. En fin, concluyamos ya nuestro análisis del epitafio de Elisa. Queremos todavía dejar una anotación menuda : cuando Garcilaso dice "Elisa soy, en cuyo nombre suena / y se lamenta el monte cavernoso ...", sin duda, ese verbo sonar está empleado a la manera virgiliana: al comienzo de la Bucólica I, encontramos aquellos famosos versos: “... tu, Tityre, lentus in umbra / formosam resonare doces Amaryllida silvas" 20 .

13 Vv. 43-44.

14 Vv. 241-48, ed. cit., págs. 202-203. Buen propagador de noticias es este río, pues, como dirá Cervantes, "no es la fama del río Tajo tal que la cierren límites, ni la ignoren las más remotas gentes del mundo" (Los trabajos de Persiles y Sigismunda, ed. cit., lib. III, cap. 8 , pág. 327).

15 Cf. J. Corell, "Dos epitafios poéticos de Saguntum", Faventia, 12-13 (1990-1991), 165-74 (cf. pág. 168).

16 Para el tópico de la supervivencia post-mortem (el difunto vive en el Elíseo, entre los dioses, y merece el mismo culto divino - véase cómo a Dafinis se le dedican aras-), cf. los consejos del rétor Menandro (s. III d. C.), en F. Romero Cruz, trad., Menandro: sobre los géneros epidicticos, Salamanca, Universidad, 1989, pág. 77.

17 Vv. 394-96, ed. cit., pág. 133.

18 Aqui utilizamos el término consolatio en cuanto componente de una composición funeral, no en cuanto género literario, sea oratorio, sea poético, equivalente al epicedion. Sobre este último término, cf. Gabriel Laguna, op. cit., pág. 252. Por otro lado, poco nos ayuda lo que nos dice López Pinciano: "los [poemas] que [se hazían] a muerte, fueron dichos primero Elegías, mas ya este nombre de especie de tristeza se hizo género, y significa a todo poema lutuoso y triste [...], y los poemas que a muertes se aplican, han tomado otro nombre, dicho Epicedio" (Philosophía antigua poética, ed. de A. Carballo Picazo, Madrid, CSIC, 1953, t. I, págs. 293-94).

19 Cf. las anotaciones de A. Ramírez Verger, "La consolatio", págs, 68-69.

20 Vv. 4-5. También Lapesa encuentra en este verbo ecos virgilianos, aunque él cita la égloga VI, vv. 43-44 (cf. Garcilaso: estudios completos, Madrid, Istmo, 1985, página 161). 
Sigamos en Garcilaso, en la Égloga II. Ahora encontramos poesía funeraria de distinto signo. En efecto, en una urna guardada por el rio Tormes se anticipan las hazañas de los miembros de la familia ducal de Alba, y, en tal narración, se introduce el relato de la muerte de don García, hijo del segundo duque de Alba. Nos encontramos aquí con un doble esquema virgiliano, si no nos equivocamos. Por un lado, la capacidad protética del río castellano se inspira en la profecía que el río Tíber hace a Eneas sobre el futuro de sus labores, y de su hijo, en Italia (Eneida, VIII, 36-65). El Tíber es un dios, y el Tormes vaticina el porvenir por "devino consejo" (Égloga II, v. 1176). Pero, además, así como Anquises, en el libro sexto de la Eneida, anuncia a su hijo los acontecimientos importantes de la historia romana, acontecimientos que narrados como futuro en realidad para Virgilio y sus lectores son pasados (se trata de una vaticinatio ex eventu), así también Garcilaso nos presenta sucesos de una familia nobiliaria que, desde la perspectiva del autor de los relieves de la urna, son futuro, aunque pasado para el poeta toledano ${ }^{21}$. En este marco de anticipación, de anticipación muy especial, según hemos visto, Virgilio introduce la figura de Marcelo, en quien el Imperio había puesto tantas esperanzas. Pero Marcelo ha muerto. Ha triunfado la mors inmatura. También Garcilaso, en el relato de las gestas ducales, nos introduce a don Garcia, hijo de don Fadrique de Toledo, segundo duque de Alba, don García que murió a los veintitrés años, en la expedición de los Gelves. Los dos eran la esperanza, y esperanza militar. Pero si Marcelo no pudo con el hado (Virgilio exclama en una condicional, que no es sino deseo irreali-

21 Para la urna y sus relieves, E. Mele propone como fuente un pasaje de Sannazaro, en el $D e$ partu $V$ irginis, en el que el río Jordán adquiere cualidades proféticas (cf. "In margine alle poesie di Garcilaso", Bulletin Hispanique, 32, 1930, págs. 218-45, cf. pág. 225). Sin negarnos rotundamente a tal aseveración, la tradición literaria de esta vaticinatio ex eventu, nos lleva más lejos: la Eneida es un excelente modelo (y en el cuerpo del texto lo justificamos). Por lo demás, el sintagma labrada y cristalina/urna (Égloga II, 1172-1173) acaso nos remita a un verso que encontramos en la descripción del escudo de Turno: "caelataque amnem fundens pater Inachus urna" (Eneida, VII, 792). Y, por cierto, en el De partu Virginis (lib. III) aparece también ese mismo sintagma caelata ... urna (v. 318). Desde luego, tanto en la obra de Sannazaro como en los versos de Garcilaso se encuentra el influjo del gran poeta latino. Las huellas virgilianas en todo el episodio del río Jordán (cf. De partu..., lib. III, vv. 281-504) son abundantísimas. Además del eco señalado, anotemos cómo el río se encuentra rodeado de ninfas, en un ambiente que remite a Geórgicas, IV, vv. 336 y sigs. (algo ya anotado por F. Arnaldi y G. Rosa, op. cit., págs. 260-61). Por si fuera poco, el Jordán nos cuenta episodios que, a su vez, ha oído de boca de Proteo, el dios profético que aparece en Geórgicas, IV, 387 y sigs. Y, por lo que respecta a Garcilaso, hay aún más huellas virgilianas en la Egloga II. Así (cf. vv. 1590-1627), el Danubio anima a Carlos V y a don Fernando, duque de Alba, a lanzarse sobre los turcos, como el Tíber, en el libro VIII citado de la Eneida anima a Eneas a enfrentarse con su futuro itálico. Y si el Tíber amaina sus ondas para que Eneas navegue hasta Evandro, el Danubio amaina las suyas para que las huestes del Emperador naveguen con facilidad contra los turcos. 
zable: "si qua fata aspera rumpas!" 22 ), don Garcia sucumbió ante las Parcas, las tres inicuas hadas ${ }^{23}$. Luego, Garcilaso se extiende comparando la agonía del infeliz joven con la pérdida de lozanía de la rosa o con la espaciada desaparición del color del lirio cortado por el arado ${ }^{24}$, tópico que, según hemos visto, se relaciona frecuentemente con el de la mors inmatura.

Garcilaso, pues, recoge el tema funerario en sus églogas, algo que hemos visto en la tradición clásica, y algo que también se estaba cultivando en la poesia europea escrita en latín, conforme ha anotado Leonard Grant ${ }^{25}$.

Pero dejemos ya a Garcilaso. Llegamos a Herrera. Como es bien sabido, el poeta sevillano compuso una égloga, en tercetos encadenados, titulada $\mathrm{Sa}$ licio a la muerte de Garcilaso de la Vega ${ }^{26}$. Ya Menéndez Pelayo vio las dos fuentes esenciales de esta composición ${ }^{27}$ : el Canto fúnebre por Bión, atribuido a Mosco ${ }^{28}$, y la Égloga V de Virgilio. No vamos nosotros a comentar aquí este poema por cuanto M. ${ }^{a}$ Teresa Ruestes Sisó ha hecho un detallado análisis ${ }^{29}$. Con todo, quisiéramos dejar una modesta nota que nos parece ha pasado inadvertida a la estudiosa herreriana. El poeta sevillano pone su poema en boca de dos pastores: Alcón y Tirsis. El primero de ellos es nombre virgiliano que aparece secundariamente en la Égloga $\mathrm{V}$ antes citada ${ }^{30}$. El segundo nombre tiene mayor interés. Se trata del pastor que en el Idilio I de Teócrito deplora la muerte de Dafnis ${ }^{31}$. Si consideramos que Virgilio en su Égloga V imita precisamente esta composición teocritea ${ }^{32}$, y que Herrera, a su vez, se hace eco del poema del mantuano, veremos que el nombre de Tirsis ha estado perfectamente elegido: Herrera probablemente ha elevado un pequeño homenaje al lejano Teócrito, el cantor de la muerte de Dafnis, quien, insistimos, subyacía en los versos de uno de sus modelos: Virgilio.

22 V. 882.

23 V. 1223 , ed. cit., pág. 172.

24 Cf. vv. 1254-1266, ed. cit., págs. 172-173.

25 Neo-Latin Literature and the pastoral, Chapel Hill. Univ. of North Caroline, 1965, págs. 306-30.

26 N. 28 en Poesía castellana original completa, ed. de C. Cuevas, Madrid, Cátedra, 1985.

${ }^{27}$ Cf. Biblioteca hispano-latina clásica, Edición Nacional, Santander, 1952, vol. IX, pág. 153.

${ }^{28}$ Se trata de un poema anónimo, según M. García Teijeiro y M. ${ }^{\mathrm{a}}$ Teresa Molinos Tejada, Bucólicos griegos, Biblioteca Clásica Gredos, 95, Madrid, 1986, pág. 302.

20 Las églogas de Fernando de Herrera. Fuentes y temas, Barcelona, PPU, 1989, págs. 299-332.

30 Dice Menalcas a Mopso: “Incipe, Mopse, prior, si quos aut Phyllidis ignis / aut Alconis habes laudes ..." (vv. 9-10).

s1 Este idilio recibe en varios manuscritos el título de Tirsis o El canto. Cf. Bucólicos griegos, cit., pág. 53, nota 1. Con todo, Tirsis también es uno de los pastores de la Bucólica VII de Virgilio.

sa Cf. F. Plessis y P. G. Lejay, Oeuvres de Virgile (47. a ed.), París, Hachette, 1973, pág. 34. Según estos mismos autores, Virgilio también se inspira aquí en el Canto fúnebre por Adonis de Bión, y en el idilio atribuido a Mosco, antes citado. 
Todavía quisiéramos hacer otra anotación al poema de Herrera. En él vemos cómo los ríos Tajo y Tormes se conmueven por la muerte de Dafnis. Ciertamente que este topos lo encontramos ya en el poema atribuido a Mosco, y tiene, desde luego, una larga historia. Así, por citar un ejemplo fuera de los limites en los que nos estamos moviendo, vemos cómo en el 874 , a la muerte de Hatúmoda, primera abadesa de Gandersheim, un presbítero, Agio, escribe un poema consolatorio, en el que los elementos de la naturaleza se conmueven ante tal desgracia ${ }^{33}$. Llegando ya a la época que nos ocupa, creemos que no sería improcedente señalar cómo en la poesía del xvi escrita en latín gozó el topos de buena fortuna. Así Juan Petreyo, que escribió en Alcalá por los años treinta del siglo xvi, al componer un epitalamio a las bodas del príncipe Felipe (futuro Felipe II) y la princesa María, nos presenta al río Tormes exultante al ver las nupcias, y más alegre por el contraste con el recuerdo doloroso del día en que lloraba la muerte de otro Felipe, sin duda, Felipe el Hermoso ${ }^{34}$. El río, pues, participa tanto del dolor cuanto de la alegría de los protagonistas.

Pero si los epitafios pueden aparecer en el marco de las églogas, según hemos visto, a veces tienen una manifestación exenta. Buen ejemplo de ello es el epitaphium que a la muerte en 1555 de la reina doña Juana de Castilla, conocida como la Loca, compuso el Brocense ${ }^{35}$. Puede decirse que en él la consolatio brilla con profusión. Verdaderamente, será difícil encontrar otro poema funerario más exento de dolor. Habla en primera persona la reina Juana, quien nos cuenta cómo muere contenta, pues sus descendientes dirigen reinos por todo el mundo. Y, además, ella misma nos habla de la subida a los cielos. Nos encontramos aqui con el makarismós, tópico de consuelo con el que se establece en la poesía funeral que el difunto ha alcanzado la inmortalidad. Buen ejemplo de makarismós encontramos en Estacio, Silvas, III, 3, vv. 22-26, en los que el poeta canta la alegría de las regiones celestes ante la llegada del difunto Claudio ${ }^{36}$.

Este poema del Brocense nos recuerda el que compuso Propercio (Elegías, IV, 11), en el cual Cornelia, difunta, consuela - también habla en primera persona- a su marido. La mujer muere serena, casi satisfecha, dirímos, por haber llevado una vida virtuosa (es decir, por haber tenido un solo marido, haber tenido tres hijos, haber sido una buena esposa, buena madre y

3s Cf. J. Gil, "El epicedio de Hatúmoda”, Faventia, 1/1, 1979, págs. 27-34.

s. Cf. Juan Petreyo, Libri quattuor in laudem Divae Magdalenae, Toleti, 1552, Biblioteca de la Universidad de Salamanca, 35395, fols. 49 y sigs. El río Tormes -otro ejemplo- llora la muerte de Isabel de Valois, tercera esposa del mismo Felipe II, en el poema que con tal ocasión compuso El Brocense, Obras, t. II, Poesía, ed. de A. Carrera de la Red, Cáceres, Institución Cultural “El Brocense”, 1985, pág. 72.

35 Cf. ed. cit., págs. 62-64.

36 Cf. la ed. de G. Laguna, pág. 80, y sus comentarios, pág. 265. 
buena hija ${ }^{37}$ ), $y$ por haber dejado a su hermano instalado en una buena posición social. Además, como tema de consolatio, el poema contiene la esperanza en una vida futura (vv. 101-102) ${ }^{38}$.

Pero el estudioso de la poesia funeraria en el siglo xvi no debe limitarse a los corpus poéticos convencionales. Es sabido que textos pertenecientes a otros géneros literarios acogen abundantes poemas, como acontece en $\mathrm{La}$ Diana de Jorge de Montemayor. En el libro IV, en el palacio de Felicia, encontramos un epitafio para el sepulcro de doña Catalina de Aragón y Sarmiento. Reproduzcámoslo:

\author{
Aqui resposa [sic] doña Catalina \\ d'Aragón y Sarmiento, cuya fama \\ al alto cielo llega y s' avecina \\ y desd' el Bórea'l Austro se derrama. \\ Matéla siendo muerte tan aína \\ por muchos qu' ella ha muerto siendo dama; \\ aqui'stáll cuerpo, el alma'llá'n el cielo, \\ que no la mereció gozar el suelo ${ }^{30}$.
}

La "voz" del epitafio la lleva la propia muerte, muerte que se nos presenta, aunque amable, en una de las modalidades clásicas, la de muerte raptora. Dentro de este topos, el sustantivo mors aparece acompañado de epítetos como dira, nigra, atra, cita, acerba, impia, inimica ... ${ }^{40}$. Aqui, el sintagma tan aina podria corresponder a un cita latino.

Como se ve, el poema se vertebra, principalmente (con alguna alusión de

37 Véase este epitafio en que una mujer también habla en primera persona, satisfecha de haber sido la primera esposa: "Viva viro placui prima et carissuma coniunx / quoius in ore animam frigida deposui. / Ille mihi lachrimans morientia lumina pressit: / post obitum satis hac femina laude nitet" (Iscrisioni funerarie romane, pág. 93, sin fechar). Tenemos aquí el anhelo de que el amor llegue hasta la muerte como cantará Horacio, al decirle a Lidia: "tecum vivere amem, tecum obeam lubens" (Odas, III, 9, v. 24).

38 Cf. también el "Epicedion in Priscillam" de Estacio (Silvae, V, 1). Para las palabras consolatorias dirigidas por la esposa, cf. vv. 177-93.

32 Cf. ed. cit. de A. Rallo, pág. 295.

40 Véase, a este propósito, J. Corell, "Dos epitafios ...", pág. 169. Del mismo autor, "El epitafio poético en honor de M. Acilius Fontanus (Sagunto, Valencia)", Faventia, 9/1, 1987, págs. 97-109 (cf. especialmente la pág. 100, en la que reproduce el epitafio en el que se ven el tópico de la muerte arrebatadora, junto con la mors inmatura, y la consolatio basada en la pervivencia de la fama). Para la muerte raptora, cf. Estacio, Silvae, II, 1, vv. 1-3, en la Consolatio a Melior por la muerte de Glaucias, que no había cumplido los doce años: "Quod tibi proerepti, Melior, solamen alumni / improbus ante rogos et adhuc vivente favilla ordiar ... (...)."

El tema de la muerte raptora y el gusto por colocar epítetos al lado de mors-muerte no son exclusivos de este período. Véase el siguiente verso del epitafio de Armengol, conde de Ausona (Vich) (correspondiente a los años 940 a 942): "Hunc fera mors rapuit..." (apud A. de los Ríos, op. cit., vol. II, pág. 333). 
tono petrarquista), sobre la consolatio, cimentada en la fama, en el goce de la vida sobrenatural y en la idea de que la vida terrena no merecía gozar de la excelsitud de la difunta. Curiosamente, en la misma novela, en otro lugar, la pastora Belisa se consuela de la aparente muerte de su amado Arsileo con idéntico argumento: “... no me parece - dice Belisa- que fueron sus [los de Arsileo] hados y mi fortuna causa de que la muerte me le quitase tan presto delante de los ojos, mas antes fue no merecer el mundo gozar más tiempo de un mozo a quien la naturaleza había dotado de tantas y tan buenas partes" "41. A este propósito recuérdese que ya Marcial afirmaba que para los seres extraordinarios la vida es breve, y con dificultad alcanzan la vejez: "Inmodicis brevis est aetas et rara senectus. / Quidquid amas, cupias non placuisse nimis" ${ }^{42}$. Probablemente todo ello hay que relacionarlo con la idea platónica de que existe un amor regido por el mundo espiritual, sublimador de las puras pasiones físicas ${ }^{43}$. En todo caso, este topos de la excelsitud de la persona amada, que vuelva a los cielos, todavía lo encontramos en la égloga Melibeo-Damón de Diego Hurtado de Mendoza. El pastor Melibeo increpa al Mundo, por la muerte de su amada Isea: "Caida es ya tu gloria y no la ves; / no eras digno, cuando ella / vivía en ti, de haber su conocencia / ni merecias tú $\tan$ gran victoria / de ser tocado de sus santos pie, / porque cosa $\tan$ bella / debia el cielo alegrar con su presencia" "4. Claro que aquí, además, acaso haya que tener presente el tópico de la donna angelicata, de tradición medieval tan honda: si la mujer es ángel, difícilmente la tierra puede contemplarla.

2. Estudiemos ahora unas pocas muestras de lo que nos atrevemos a llamar con temor elegía, aunque los autores no siempre le otorguen tal nombre, según veremos. Pero que nuestro término no es incorrecto nos lo muestran no sólo los componentes de estas composiciones: laudatio y lamentatio por la muerte de un difunto, además de la consolatio ${ }^{45}$, sino, en el caso de la poe-

41 Cf. La Diana, lib. III, ed. cit., pág. 248.

4 Cf. Epigrammaton libri, VI, 29, vv. 7-8.

43 Cf. El banquete, $180 \mathrm{~d}$ y sigs. Tal idea tiene eco, por ejemplo, en Leucipa y Clitoforte de Aquiles Tacio, lib. II, según M. Brioso y E. Crespo, Biblioteca Clásica Gredos, 56, Madrid, 1982, págs. 228-29. Para la distinción entre el amor de Eros, sublimador de lo físico, y el de Afrodita, puramente sensual, cf. la introducción de C. García Gual en El banquete de Platón, trad. de F. García Romero, Madrid, Alianza, 1989, págs. 28 y sigs.

4 Cf. vv. 45-53, de Diego Hurtado de Mendoza, Poesía completa, ed. José I. Díez Fernández, Barcelona, Planeta, 1989, págs. 68-69. Para varios influjos de Marullo en algunos poemas funerarios de Hurtado, cf. J. P. G. W. Crawford, "Don Diego Hurtado de Mendoza and Michele Marullo", Hispanic Revieww, 6, 1938, págs. 346-48.

45 Aunque, como es sabido, la elegía no trata de un solo tema, sino que se caracteriza por la pluralidad de su contenido. Con todo, en un principio era manifestación del dolor por la muerte de alguien, según Horacio, Ars Poetica, 75: "Versibus impariter 
sía escrita en latin, el hecho de que el poeta se sirva de los disticos, llamados elegíacos, precisamente.

El tema de la apotheosis, extraordinariamente consolador, aparece con claridad en el poema que Sánchez compuso en 1568 a la muerte del príncipe Carlos ${ }^{4}$. Como que vertebra todos los versos y da incluso nombre a la composición. El dolor que el poeta siente por la pérdida del príncipe queda compensado por el saber que se encuentra ya junto a Escorpión, en el mismo lugar que Virgilio - y el Brocense explícitamente lo recuerda ("hanc sedem Augusto voverat ante Maro" ${ }^{47}$ )-, reservaba a Augusto. La creencia clásica de la subida de algunos grandes hombres al cielo se ve, en efecto, en Virgilio, para quien Augusto tiene ya un lugar reservado entre los astros, en la constelación de Escorpión, según nos cuenta el poeta en las Geórgicas (I, 35). Por eso Horacio, seguidor de esta esperanza, en Carmina (I, 2), pide a Augusto que no se vaya enseguida a los cielos para realizar en la tierra el benéfico papel de pacificador ${ }^{48}$.

$\mathrm{Y}$, desde luego, tal tipo de manifestación de consuelo no falta en la poesía escrita en latín por los humanistas. Así, Marullo en la "Consolatio ad Andream Matthaeum Aquavivium de morte Iulii patris" (Epigrammata, I, 48) 49 recoge el tema de la subida del alma hasta los astros.

iunctis querimonia primum." Cf. V. Cristóbal López, trad. de Ovidio, Amores, Arte de amar, Sobre la cosmética del rostro femenino, Remedios contra el amor, Biblioteca Clásica Gredos, 120, Madrid, 1989, pág. 26. Para el origen poligenético de la elegía latina, cf. Archibald A. Day, The origins of latin love-elegy, Oxford, 1939.

46 En 1558 ya escribió el Brocense su In obitum Q. Caroli Caesaris Imper. Hispaniarum Regis Prosopopaeia, en el que recoge el tema de la apotheosis: Carlos evolat ad superas summa per astra domos, v. 49, ed. cit., pág. 66 .

47 Cf. v. 24, ed. cit., pág. 70.

48 Este tipo de poemas latinos hay que relacionarlo, además, con los panegíricos imperiales. Cf. Laguna, op. cit., págs. 252-54. Cf., además, M. ${ }^{\mathrm{a}} \mathrm{J}$. Cantó, C. Codoñer y A. Ramos, "Oratoria", en C. Codoñer, ed., Géneros literarios latinos, Salamanca, Universidad, 1987, págs. 13-38. Cf. otra muestra de la apotheosis en el "Epicedio en honor de Marcelo" de Propercio (III, 18, vv. 31-34).

10 Cf. Carmina, ed. cit. de A. Perosa, págs. 20-22. Pero en Marullo la consolatio se basa, sobre todo, en la pervivencia de la fama: "Vivit honos, vivunt benefacta virumque labores, / et fugit hostiles fama decusque rogos" (vv. 35-36, pág. 21). Nótese cómo este último verso de Marullo nos lleva a fray Luis (no quiere ello decir que, necesariamente, el sabio salmantino tomara su expresión del italiano. Alcina aduce otros paralelismos) : "E1 tiempo nos convida / a los estudios nobles, y la fama, / Grial, a la subida / del sacro monte llama, / do no podrá subir la postrer llama" ("Al Licenciado Juan de Grial", XI, 16-20, ed. (3. a) de J. F. Alcina, Madrid, Cátedra, 1989, pág. 133). La farna, en Marullo, se basa en las buenas acciones realizadas, no en la altura del linaje recibido: "Si genus audieris, spernes: mirabere gesta. / Illud fortunae est, hoc opus ingenii" ("Epitaphium Francisci Sfortiae", Epigrammata, n. ${ }^{\circ} 20$, ed. cit., pág. 10). Ideas éstas que nos llevan al prólogo del Lasarillo (cf., para el origen clásico de tales afirmaciones, F. Rico, “'El deseo de alabanza'” [1976], en su Problemas del "Lasarillo", Madrid, Cátedra, 1988, págs. 57-68). Para el eco de Marullo en los humanistas, cf. Walter Ludwig, "The Origin and Development of the Catullan Style in Neo-Latin Poetry", en P. G. Godman 
Tornando a composiciones escritas en romance, señalemos que Francisco de Figueroa escribió un poema en tercetos encadenados "A la muerte del Príncipe ... don Carlos, hijo ... del Rey don Felipe II" "so. No hará falta justificar la inclusión de una obra en tercetos encadenados en este grupo. Tal forma métrica se consideró desde muy pronto "traducción" de la elegía (así en Rengifo) ${ }^{51}$. En dicha composición, el poeta pide al principe que consuele a España con sus propias palabras, cuyo resumen podría ser éste: 'Yo estoy feliz en la Gloria, y aquí te resulto más provechoso que en la Tierra.' Y el propio don Carlos nos hace una pequeña descripción de cuál es su situación en el Paraíso. En definitiva, se trata, otra vez, de una consolatio realizada por el propio difunto.

El propio Figueroa tiene un soneto "A la muerte de un hijo de Garcilaso de la Vega, que murió, como su padre, en la guerra" ${ }^{52}$. Que se nos permita tratar de él en este apartado. El soneto, en efecto, se consideró desde el siglo xVI ${ }^{33}$ como "traducción" de los epigramas latinos, relacionables con la elegía, según es bien sabido ${ }^{54}$. Retomando, pues, el curso de la exposición, digamos que en ese soneto encontramos dos elementos clásicos de la poesía funeraria. Por un lado, el tema de la mors inmatura: "... tierno pimpollo ya de flores lleno" (v. 3); por otro, el de la consolatio, basada en la creencia de una vida futura: "Y una misma también piadosa mano / os traspuso en el cielo, a do las flores / de ambos han producido eternos frutos" (vv. 9-11). Dentro del tema de la consolatio, figura la exhortación a reprimir el llanto: "No os llore, como suele, el mundo en vano, / mas conságreos altar, ofrezca olores / con voz alegre y con semblante enjuto" (vv. 12-14). Esta última invitación para elevar altar a la memoria del difunto nos vuelve a recordar la erección de aras a Dafnis, en la Égloga V de Virgilio.

3. Dejemos ahora anotadas dos particulares muestras de poesía funeral, inspiradas en un mismo lugar virgiliano. Con motivo de la muerte del príncipe

y O. Murray, eds., Latin poetry and the classical tradition. Essays in Medieval and Renaissance Literature, Oxford, Clarendon Press, 1990, págs. 83-97 (cf. pág. 196). Cf. también J. F. Alcina, "Petrarquismo latino en España, II. Hernán Ruiz de Villegas y la imitación de Marullo", Nova Tellus, 4, 1986, págs. 43-61. Cf., además, Carol Kidwell, Marullus soldier poet of the Renaissance, London, Duckworth, 1989. Véase también nuestra nota 44.

so Elegía VI, n. ${ }^{\circ}$ 61, en Christopher Maurer. Obra y vida de Francisco de Figueroa, Madrid, Istmo, 1988, págs. 320-21. E1 editor lo da sólo como "probable" de Figueroa.

81 Cf. Iuan Díaz Rengifo, Arte poética española.... Salamanca, Miguel Serrano de Vargas, 1592, Biblioteca Universitaria de Salamanca, 34289 y 34707, cap. LVII, páginas $60-61$.

${ }^{22} \mathrm{~N}^{\circ} 14$, ed. cit., pág. 242.

ss Cf., por ejemplo, Rengifo, op. cit., cap. XLII, págs. 48-49.

* No queremos decir que no haya problemas para relacionar, al menos genéticamente, ambas formas literarias. Cf., para este complejo aspecto, Carmen Castrillo González, "Elegía", en Carmen Codoñer, ed., Géneros, págs. 87-113 (cf. pág. 91). 
Juan, hijo de los Reyes Católicos, en 1497, el humanista Pedro Mártir de Angleria escribió un poema (en 22 dísticos elegíacos) que lleva como titulo "Petri Martyris Angli Mediolanensis de obitu Catholici Principis Hispaniarum qui Salmantice absente Regina hominem reliquit, carmen flebile quom consolatoria in calce" 55 . Se trata del clásico epicedio en el que se integra, como ya lo dice el propio título, una consolatio final, basada en la apotheosis: el príncipe Juan se encuentra ya entre los astros. Resulta interesante cómo el humanista ha introducido en sus versos un corto lamento imaginario de la madre Reina, que a nosotros nos hace recordar, en efecto, el planto de la madre de Eurialo en la Eneida (libro IX), lamento que volveremos a encontrar en el segundo texto que estudiaremos luego. Digamos ahora que ya Juan de Mena se inspira en ese locus de Virgilio (Laberinto de Fortuna), en el llanto vertido por la madre de Lorenzo Dávalos ${ }^{56}$. A su vez, este pasaje de Mena sirve de inspiración al lamento de la madre de Leriano, en la Cárcel de amor de Diego de San Pedro, lamento que deja huella en el llanto de Pleberio, en La Celestina ${ }^{57}$.

La fortuna de estos versos virgilianos debería ser estudiada con detenimiento. Antes de señalar otro eco en las letras hispanas, digamos que Iacopo Sannazaro, en el De partu Virginis (1526), al introducir el llanto de la Virgen Maria ante la cruz, imita claramente el planto virgiliano ${ }^{58}$.

Pero volvamos a España. Y demos un gran salto cronológico. Entremos

5s Apud P. M. de Anglería, Opera: Legatio babylonica, Occeani decas, Poemata, Epigrammata, Sevilla, Jacobo Corumberger, 1511, Biblioteca Universitaria de Salamanca, 31200 , fols. [i viii-i viii v. ${ }^{\circ}$ ]. Para una descripción de este impreso, cf. ahora C. Codoñer, en su ed. de A. de Nebrija, Comentario al poema "In Ianum" de Pedro Mártir de Angleria. Salamanca, Universidad, 1992, págs. 28 y sigs. Cf. también Félix G. O1medo, Diego Ramirez Villaescusa (1459-1537) fundador del Colegio de Cuenca y autor de los cuatro diálogos sobre la muerte del Príncipe don Juan, Madrid, Edit. Nacional, 1944, págs. 312-13.

56 Algo que ya señaló el Brocense en su ed. de El Laberinto, Salamanca, 1582, dato tomado de la ed. de Louise Vasvari, Madrid, Alhambra, 1976, pág. 180, nota a la copla 205. Tal influjo lo señala también ahora V. Cristóbal en su introducción a Virgilio, Eneida, Biblioteca Clásica Gredos, 166, Madrid, 1992, pág. 109, nota 247. En cambio, F. Rico prefiere situar tal lamento dentro de la tradición religiosa del planctus Mariae (cf. "El Duelo que fizo la madre de Lorenzo Dávalos", en Primcra cuarentena y Tratado general de literatura, Barcelona, E1 Festín de Esopo, 1982, págs. 63-64). Pero las dos corrientes son perfectamente compatibles. Véase lo que en el cuerpo del texto decimos enseguida a propósito del planto de María en el De partu Virginis de Sannazaro.

${ }^{57}$ Cf., sobre todo ello, D. Sherman Severin, "From the Lamentations of Diego de San Pedro to Pleberio's Lament", The Age of the Catholic Monarchs, 1474-1516. Literary Studies in memory of Keith Whinnom, ed. by A. Deyermond and I. Macpherson, Liverpool, University Press, 1989, págs. 178-84. Con todo, Sherman no alude para nada a Virgilio. Permitasenos añadir que el tono de Diego de San Pedro, en el pasaje aludido, o el de F. de Rojas (ya en el planto de Melibea por la muerte de Calisto, ya en el de Pleberio por la muerte de su hija), llega, nos parece, hasta la Diana de J. de Montemayor, en el llanto de Belisa por la muerte de Arsileo, lib. IV, ed. cit., pág. 296.

s8 Cf. lib. I, vv. 344 y sigs. 
en el siglo xvir. La muerte de Felipe III origina abundante composición de poemas en latin y en castellano ${ }^{59}$. En la Universidad de Salamanca también se lloró la muerte de Felipe III, en un certamen poético. Dentro de uno de los apartados, los poetas habrian de presentar, en versos latinos, en hexámetros, a España que llora la muerte de su hijo, con imitación -que se impone en las "bases" del Certamen- del lamento citado de la madre de Eurialo. Otra vez un mismo modelo virgiliano sirve para llorar a una persona de sangre real. Entre los poemas presentados, destaca el de Blas López, catedrático de Prima de Latinidad ${ }^{\infty}$. Sólo anotaremos aqui algunos rasgos de tal poesía funeraria. En el verso "Orique os impressa tuo sic oscula figo?" (v. 6) encontramos el clásico beso postrero al agonizante, del que tenemos infinitos ejemplos en la antigüedad. Recordemos sólo la Consolatio ad Claudium Etruscum de Estacio: “... animaeque supremum / frigus amat" (se refiere al hijo, que recoge el último aliento del padre) ${ }^{61}$.

Uno de los gestos propios del duelo, en el trenos, es la queja de la dureza de los dioses. Asi, Estacio nos describe al esposo, desesperado, en el Epicedion in Priscillam ${ }^{62}$. Tal rasgo no falta en el lamento de España, madre de Felipe, que pide a los criados: "crudelia mecum / Astra vocate simul ..." (vv. 30-31).

Los tres últimos versos, en los que Blas López pinta el desfallecimiento de España, madre del Rey (“... labantem / Suscipite, o famulae, lectoque imponite; namque / Verba dolor, vocemque animumque intercipit, ingens"), se refieren a los versos 500-502 de la Eneida, IX, en los que Virgilio describe el dolor enloquecedor de la madre de Euríalo. Estos momentos de climax dolorosos son frecuentes en la poesía funeral. En el ya tantas veces citado poema de Estacio, la Consolatio ad Claudium Etruscum, éste, enloquecido, quiere lanzarse a la pira funeraria, y "vix famuli comitesque tenent" ${ }^{63}$. Blas López ha sido más suave: nos presenta a España, a la madre del Rey, que, en el summum del dolor, desfallece.

4. Como coda de este trabajo, querriamos dejar aquí una simple sugerencia. Creemos que en el famoso soneto quevedesco Amor más poderoso que

59 Cf. las anotaciones de J. M. Micó, en Luis de Góngora, Canciones y otros poemas en arte mayor, Clás. Castellanos nueva serie, 20, Madrid, 1990, pág. 176.

60 Vid. el texto en [fray Ángel Manrique] Exéquias. Túmulo y pompa funeral que la Universidad de Salamanca hizo en las honras del Rey ... Felipe III .... Salamanca, Antonio Vázquez, 1621, B. Univ. de Salamanca, 27300, págs. 223-25. Sobre este fray Ángel Manrique, luego obispo de Badajoz, damos bibliografía en nuestro estudio "Notas sobre la recepción del Poliziano latino en España: una monodia del catedrático salmantino Blas López", Criticón, 55, 1992, págs. 41-52 (cf. pág. 46, nota 25).

61 Cf. vv. 19-20, ed. cit., pág. 80 .

62 Cf. Silvas, V, 1, vv. 20-23.

es Cf. v. 178, ed. cit., pág. 88. 
la muerte se inserta de manera espléndida el tópico de la consolatio que hemos estudiado. Todo él, en definitiva, no es más que una forma de consolarse ante la muerte con la idea de que hay algo que permanece y supera a ésta. Quizá parezca osado relacionar este soneto amoroso con la poesía funeraria. Sin embargo, es bien sabido el entrecruzamiento de géneros y temas que se produce en la poesia de los Siglos de Oro. Por otra parte, tal relación resulta menos sorprendente si nos lanzamos osadamente a buscar una de las posibles fuentes de tal composición. Mucho se ha trabajado ya en este sentido, y posiblemente las soluciones que se han dado a este enigma no vayan descaminadas $^{64}$. Nosotros querríamos también dejar nuestra hipótesis. Creemos que en este soneto hay un eco properciano. En la elegía séptima del libro cuarto, Propercio nos muestra cómo su amada Cintia, difunta, regresa en sueños y se le aparece. La frontera entre el reino de los muertos y el de los vivos no es infranqueable (no lo es en Propercio; no lo es en Quevedo): “... letum non omnia finit / luridaque evictos effugit umbra rogos" (vv. 1-2). Cintia profiere reconvenciones al amado. Pero termina con una consolatio: la sobrevivencia del amor, aunque sea en la unión de los despojos: "mecum eris et mixtis ossibus ossa teram" (93-94). Esos despojos del poeta y de Cintia serán polvo enamorado ${ }^{65}$.

Con todo, las lineas anteriores no quieren expresar la confianza de que aquí se encierre toda la clave diacrónica del poema. En realidad, a nosotros lo que más nos interesa no es propiamente establecer una fuente exacta para este soneto de Quevedo. Nuestro afán se cifra en insertar los versos del poeta barroco en una tradición clásica, tradición de poesía funeraria, en la que se pretende establecer comunicación entre las dos riberas: entre el mundo de los muertos y el mundo de los vivos. Y en esa tradición, a veces, se afirma que el amor, osado, rebasa los muros del olvido. El hilo diacrónico se aleja hasta la literatura griega, claro. Y asi, Mosco, en su famosísimo "Amor fugitivo" nos pinta a Afrodita realzando el poder de su hijo, el Amor, traspasador de la muerte: “... sus dardos [los de Cupido, según Afrodita] tienen alcance grande: alcanzan hasta el Aqueronte y el alcázar de Hades" "6. Como que el dios Hades se enamoró de Perséfone.

No existe barrera infranqueable entre el mundo de los vivos y el mundo

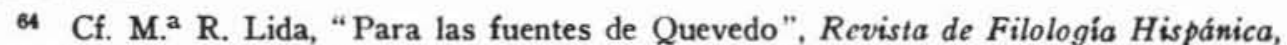
1, 1939, págs. 369-75 (cf., concretamente, págs. 373-75); cf. F. Rico, en Biblioteca, páginas $276-80$, y pág. 287.

65 La relación de estos últimos versos propercianos con el final del soneto de Quevedo fue ya establecida, aunque sin mayor detenimiento, por A. Ramírez Verger en "Una lectura de los poemas a Lesbia y a Cintia", Estudios Clásicos, 90, 1986, págs. 6781 (cf. pág. 75). Pero Ramírez Verger se inclina por la elegía 19 del libro I, como fuente del soneto quevedesco.

so Vv. 14-15. Cf. M. Garcia Teijeiro y M. ${ }^{a}$ Teresa Molinos Tejada, Bucólicos Griegos, pág. 290. 
de los muertos, según uno de los hilos de la tradición. Curiosamente, Teócrito nos presenta al desamorado Dafnis negándose porfiadamente a tan noble sentimiento incluso en el más allá. Estas son sus palabras: "Dafnis hasta en el Hades será para Amor dolor penoso" ${ }^{67}$.

Pero vengamos a un tiempo mucho más cercano a Quevedo. Nos preguntamos si no habrá que tener en cuenta, además, unos versos de Garcilaso, en la Égloga III, en los que demuestra la voluntad de cantar a doña María, esposa de don Pedro de Toledo, no sólo en vida, sino en la muerte también: “... mas con la lengua muerta y fría en la boca / pienso mover la voz a ti debida; / libre mi alma de su estrecha roca, / por el Estigio lago conducida, / celebrando t' irá, y aquel sonido / hará parar las aguas del olvido" ${ }^{68}$. El poeta Garcilaso, como Orfeo, penetra en los reinos subterráneos, dominador de las tinieblas con su voz poética. Acaso todo poeta, también Quevedo, desde luego, es un Orfeo, desafiador del reino de los muertos.

Todavia una nota: nos preguntamos si en la expresión feliz polvo enamorado, en la que se cifra la unión de la muerte (polvo) y el triunfo de la vida post-mortem (enamorado) no se encuentra un sutilisimo recuerdo del mito del ave Fénix, resucitadora en sus cenizas, como el amado resucita, por el calor de la llama amorosa, en las suyas ${ }^{69}$.

Terminemos, La poesia funeraria española de los Siglos de Oro se presenta, pues, rica en elementos clásicos. Aquí, apresuradamente, nos hemos limitado a señalar algunas líneas, acaso como anticipo de futuros trabajos.

67 Cf. Idilio I, vv. 102-103, en Bucólicos, pág. 59.

o Vv. 11-16, ed. cit. de Rivers, pág. 193. Por lo demás, señalemos como final, que la metáfora llama = amor no es de exclusiva estirpe petrarquesca (filiación estudiada por C. Blanco Aguinaga, “'Cerrar podrá mis ojos'... Tradición y originalidad" [1962], en Francisco de Quevedo, ed. de G. Sobejano, Madrid, Taurus, 1978, págs. 300-318). F. Rico ha citado oportunamente Eneida, IV, 66 (apud Biblioteca, pág. 287). Véase, además, este verso de Estacio (Silvae, V, 1, v. 56), en el que se alaba a la difunta Priscila: "unum secretis agitare sub ossibus ignem".

60 El ave Fénix es un elemento consolador de la poesía funeraria barroca. Cf. un ejemplo en la "Octava fúnebre en el sepulcro de la Señora Reina doña Margarita" de Góngora (ed. cit. de Micó, págs. 233-34, quien añade otros ejemplos). 